\title{
Walking Corpses and Kindly Neighbours: Retrospective Accounts of AIDS Stigma in Western Uganda
}

\author{
Amy Kaler ${ }^{1}$, Arif Alibhai ${ }^{1}$, Walter Kipp ${ }^{1}$, Tom Rubaale ${ }^{2}$, Joseph Konde-Lule ${ }^{3}$ \\ ${ }^{1}$ University of Alberta, Edmonton, Canada; ${ }^{2}$ Kabarole District Health Authority, Kabarole, Uganda; ${ }^{3}$ Makerere University School of \\ Public Health, Kampala, Uganda. \\ Email: akaler@ualberta.ca, amykaler@gmail.com
}

Received April 19 ${ }^{\text {th }}$, 2012; revised May 31 ${ }^{\text {st }}, 2012$; accepted June $6^{\text {th }}, 2012$

\begin{abstract}
Stigma has been of tremendous concern in the AIDS epidemic. In this paper we investigate reported experiences of stigma in western Uganda, as related by coresidents treatment partners (TPs) of people receiving treatment through a community-based treatment programme. A survey $(n=110)$ and open-ended interviews $(n=30)$ were used. We found that while stigma persists, it is balanced by kindness and sympathy expressed by relatives and neighbours. Stigma experiences involve isolation and gossip, rather than harassment or violence. We argue that the persistence of isolating behavior may be related to 1) practical concerns about avoiding requests for assistance coming from families of people with AIDS; and 2) the perception that people with AIDS are "walking corpses", in a liminal state between life and death. The perception of AIDS as a death sentence appears to be a stronger driver of stigma than perceptions of sexual misbehaviour or promiscuity in the acquisition of AIDS. We argue that treatment has the potential to reduce stigma because it permits a repeal of this perceived death sentence.
\end{abstract}

Keywords: Stigma; Antiretroviral Treatment; Uganda; Community; Household

\section{Introduction}

Since the beginning of the global AIDS epidemic, stigma has been of tremendous concern. AIDS stigma has been referred to as the "third epidemic", a social plague following the biomedical epidemics of HIV infection and then AIDS sickness. Stigma has been posited as the cause of harassment, isolation and demoralization of people with AIDS, and as a barrier preventing people at risk from getting tested for HIV or accessing AIDS treatments (though see [1] for a dissenting view of stigma as a major impediment to treatment ${ }^{1}$ ).

In the international media, shocking incidents like the murder of Gugu Dhlamini suggest that stigma looms large. In a widely cited 2006 piece for the New York Times, Tina Rosenberg claimed that stigma kept people from protecting themselves against HIV:

Mothers sometimes reject nevirapine. People decline AIDS tests. Some sick people refuse to take free antiretrovirals. Some orphans will starve-even though help is available-rather than make the shameful admission that their parents died of AIDS. And of course, millions of

\footnotetext{
${ }^{1}$ Interestingly, when administrators of African AIDS NGOs were asked to list the three most important challenges to their prevention work, only 33\% placed stigma in the top three [3] (Benotch et al., 2008). However, this figure was used by the article's authors to bolster their claim that "reducing the burden of stigma is critical to fighting the epidemic in Africa” (330).
}

people who know better continue to risk their lives every time they have sex [2], (see also [3]).

Official pronouncements at all levels also emphasize the centrality of stigma. For example, in the lead up to World AIDS Day in 2002, Peter Piot sounded the antistigma note which characterized many of his official pronouncements as head of UNAIDS: that

Discrimination and stigma continue to stand as barriers. ... Stigma harms. It silences individuals and communities, saps their strength, increases their vulnerability, isolates people and deprives them of care of support. We must break down these barriers or the epidemic will have no chance of being pushed back [4].

Ban Ki Moon, the Secretary General of the United Nations, devoted his address at the 2008 World AIDS Conference to "the stigma factor". Moon argued that

Stigma remains the single most important barrier to public action. It is a main reason why too many people are afraid to see a doctor to determine whether they have the disease, or to seek treatment if so. It helps make AIDS the silent killer, because people fear the social disgrace of speaking about it, or taking easily available precautions. Stigma is a chief reason why the AIDS epidemic continues to devastate societies around the world [5].

Although stigma is routinely presented as a major challenge, if not the major challenge, the empirical aca- 
demic literature on AIDS stigma is a bit more equivocal. While not discounting the enormous impact of stigma on individuals and societies, the literature suggests that its prevalence and intensity is variable.

Most discussions of AIDS stigma start with Goffman's definition of stigma as "spoiled identity", whereby individuals are "marked" as unworthy or undesirable [6]. Stigma is that which discredits individuals, so that others treat them as different and therefore to be shunned or treated badly. AIDS is assumed to be a stigmatizing condition, like health conditions such as leprosy and cancer, because it is life-threatening, infectious, and its modes of transmission are associated with behaviours already stigmatized [7-10]. Stigma is enacted through activities such as segregation, avoidance, negative gossip, physical violence, and emotional repudiation directed at those who bear the stigma. Fear of stigma leads individuals to avoid acknowledging their own potentially stigmatizing status, hence the popularity of the "breaking the silence" motif in workshops or seminars on AIDS stigma.

While most research focuses on stigma as an individual-level phenomenon, some researchers have called for a more "socialized" view of stigma, in which it is conceptualized as an attribute of social situations marked by inequality and structural violence $[11,12]$. However, this alternate understanding of stigma is difficult to translate into empirical research, because individual perceptions and beliefs are easier to measure with the conventional tools of health sociology than are complex and subtle inequalities.

Most large-scale research also focuses on the perpetration of stigma-the stigmatizing beliefs held by the "general population"-rather than the experience of being stigmatized, so that it is also impossible to difficult to determine the extent to which stigma throws up obstacles in the lives of those who are HIV-positive. This research typically takes the form of asking respondents to indicate agreement or disagreement with a series of normative statements (e.g. "People with AIDS should be isolated in particular places") or to say what they would do in hypothetical situations (e.g. "Would you buy a tomato from someone with AIDS?”). While such results can be easily correlated with variables such as gender, age, or religion, their value as predictors of the damage actually done by stigma, as experienced by the bearers of that stigma, is unclear. Examples of such research on stigma in highprevalence African communities include [13-25]. These authors variously conclude that stigma is multidimensional, that stigmatizing attitudes and beliefs are unevenly distributed within populations, and that shame, blame and aversion are the most common expressions of stigma.

Nyblade et al. [23] is fairly representative of this research. This large study involved 730 interviews and focus groups in Ethiopia, Tanzania and Zambia, and concluded that stigmatization of people with AIDS was pervasive and was linked to social norms surrounding sex. The study found that sympathy and compassion often coexisted with stigmatizing attitudes or behaviours, and more extensive and accurate discussion of AIDS as well as educational programming targeting stigma were necessary. However, such interventions have had only modest success $[26,27]$.

This current study, by contrast, builds on the limited number of qualitative studies which have examined the experience of stigma as narrated by the people who are presumed to be vulnerable to it. While these studies are small-scale and usually not quantifiable, they suggest the variability and complexity of stigma experiences among different communities. Chimwaza and Watkins [28], based on a study of 12 households affected by AIDS in rural South Africa, found that people in these households perceived themselves as having been targets of stigma by their neighbours, both because of the common attribution of sexual promiscuity to people with AIDS and because of their household's descent into poverty following the loss of breadwinners. Thomas concurred in her study of 14 solicited diaries from people with AIDS or their caretakers in northern Namibia. She found that "the stigma attached to HIV/AIDS can result in considerable intra-household tension and breakdown of key social support networks" [29] (3174). Both [29,30] noted that stigma appears to grow over the course of the illness, as it becomes increasingly clear that the illness really is AIDS and the patient will not recover.

These bleak assessments contrast with Chimwaza and Watkins, who spoke with 15 caregivers for people with AIDS in rural Malawi. While respondents were burdened by tremendous poverty and in some cases a reluctance to acknowledge AIDS as the cause of sickness, they also received sympathy and support from their neighbours, in the form of visits, prayers, or material contributions. The authors write that "there was little evidence that either patients or caregivers were stigmatized... friends and relatives provided moral and social support to the patients by sitting with them and cheering them up, and to the caregiver by sympathizing with her burdens" [28] (806). In the same vein, and of great relevance to this study, Kipp et al.'s work with caregivers for people with AIDS and health volunteers in Kabarole District in Uganda found that "the attitude towards AIDS patients by relatives and friends has changed from highly stigmatizing to more understanding and sympathetic... neighbours show love and concern by coming to visit and sometimes pray with the patients” [31] (10).

\section{Methods}

This study is based on surveys and interviews with 
treatment partners (TPs) of people who were receiving antiretroviral treatment through a community-based distribution programme in Kabarole, western Uganda. The survey component was carried out with all co-resident TPs - that is, not the patients themselves, but their spouses, parents, children, and siblings, who lived together with the patient. The patients had begun treatment between February and November 2006, and their TPs were surveyed roughly 14 months after their patient had begun treatment. At the time of writing, 110 out of 136 coresident $\mathrm{TPs}^{2}$ had been surveyed. Ethical clearance for this study was received from the University of Alberta.

The first author chose every sixth name from a list of all coresident TPs, and then by added and substituted names so that the interview sample approximated the survey population as closely as possible, with respect to genders, ages, and relationships to the client. The interviews were conducted in March and April 2008 in TPs' homes by two experienced female interviewers, carried out in either Rutooro or Rukiga, depending on the TP's preference, and taped, translated and transcribed in Uganda. Interview transcripts were analyzed in Canada by the first author, using $\mathrm{N}^{*}$ Vivo software. Thirty such interviews were completed, and the first author was present for roughly a third of them.

The survey population and the interview sample had a definite feminine skew, as $64 \%$ of the co-resident TPs were women. They had a variety of relationships to their patients, the most common of which were child TP/parent patient ${ }^{3}$ (39\%) and spouse TP/spouse patient (25\%), with the rest being siblings, aunts/uncles and in-laws. Almost all the TPs had been caregivers for their patient during the worst days of AIDS sicknesses, to the extent that "TP" and "caregiver" were virtually synonymous ${ }^{4}$. In the text, TPs are referred to using randomly generated numbers in order to preserve confidentiality.

\section{Setting}

The part of Uganda in which Kabarole District is located-near the border, west of Lake Victoria-was the first region to be hit by the AIDS epidemic, beginning probably in the late 1970s. The first prevalence study in Kabarole, carried out between 1991 and 1993, found prevalence at antenatal clinics in the district ranged from a high of $28 \%$ in urban clinics, to a low of $10 \%$ in rural ones [32,33]. In 1995, a random sample of 1036 Kaba-

\footnotetext{
${ }^{2}$ The other TPs did not reside with the patients - they were usually neighbours or friends.

${ }^{3}$ The great majority of these parents were mothers, especially mothers whose husbands or male partners had died or abandoned them, leaving the mother in charge of a single-parent household.

${ }^{4}$ Although almost all TPs had provided care to patients, they were not necessarily the only caregivers. As [36] demonstrates, in Kabarole caregiving duties were often shared out among various family members, meaning that the impact of caregiving was also shared.
}

role households found that $34 \%$ had a family member sick, dying or deceased from AIDS [34]. Interviews from an earlier iteration of this present study also attest to the persistence of AIDS over the past few decades. For example, one married man whose wife is on treatment said that in his childhood

[People] would say silimu kills badly, it makes people lose too much weight, and I also used see them. I saw my aunt who was sick at home, she lost a lot of weight and lost her hair and her face shrunk, a woman who had cheeks [who had been plump]. I thank God I survivedGod must have seen my heart [i.e. fulfilled his desire to survive]. I grew up very scared of that disease [35].

Individual family histories bear out the historical depth of AIDS in Kabarole, as in the case of one man interviewed in 2008, who had seen his son, his grandson, his grand-daughter-in-law and his great-grandson all contract HIV; or another man who was rumoured to have had three wives die from AIDS, the first one 25 years ago.

Since peaking in the early 1990s, reported prevalence has decreased in Kabarole to $11.6 \%$, but this is still higher than the estimated overall prevalence for Uganda of $6 \%$ [36]. Some of this decline is undoubtedly due to switching from clinic-based sampling to populationbased sampling, but local accounts of the epidemic also say that AIDS has slowly declined. Given the extent to which HIV has permeated this community over the last few decades, it is difficult to sustain the view that HIV is a curse visited on social deviants. Interviews from [35] support this idea, as residents of Kabarole said that they believed stigma had decreased as the more and more people saw their acquaintances and relatives becoming sick $^{5}$.

At that time [1980s] if a person could get sick of AIDS, they would laugh at you-point fingers at you, gossip at you. They ran away from you, compared to these days. They even thought it was contagious [through casual contact]. ... Now that it is no longer a secret because it can catch everyone, today it is me and tomorrow it is someone else.

Despite the normalization of AIDS in this district over the last three decades, it is still not a socially neutral condition, as we demonstrate below.

\section{AIDS and Stigma in Kabarole}

It is very difficult to generalize about the extent or intensity of AIDS stigma in Kabarole. In both the interviews and the survey, respondents did not report a tremendous amount of stigma, nor did they report that their communities were entirely free from it. In the survey, 59\% of respondents said that "some people in their community" were sympathetic to people with AIDS, compared to

\footnotetext{
${ }^{5}$ See [37] for similar speculation about South Africa.
} 
33\% who said that "most people" were sympathetic and $5 \%$ who said that most people were not sympathetic. However, survey respondents were not asked whether they themselves had encountered a lack of sympathy as a result of having AIDS in the households. By contrast, in the interviews, a more nuanced picture of experiences with stigma emerges.

Interview respondents were not asked directly about stigma (a word which, when translated in Rutooro, means something analogous to "shunning"6 $)$. Instead, they were asked "how did the neighbours treat you when [client] was sick with AIDS?”

The most common response was to state either that neighbours had been helpful or kind, or that the neighbours had treated the household the same way as they had even before AIDS struck. These two responses are amalgamated in Table 1, as indicating the absence of stigma. Over a quarter said that they had experienced negative treatment, which almost always took the form of either isolation or negative gossip. Provocative harassment or violence of any form was never mentioned.

However, the large proportion reporting that no one knew about the presence of AIDS in their household is surprising. This figure may reflect three different scenarios: first, AIDS was indeed a successfully-guarded secret; second, interview respondents did not want to reveal details of their interactions with neighbours during a painful period of the household's history; or third, neighbours may have known or suspected the presence of AIDS but were too tactful to express their suspicions to members of the sick person's household. We suspect, although cannot prove, that the third is the most likely, given how widely recognized the symptoms of AIDS were.

\section{Ambiguous Kindness of Friends and Neighbours}

Many interview respondents reported acts of great kindness from people around them. While close relatives came in for criticism for not living up to their responsebilities (such as husbands or fathers who abandoned the

Table 1. Interview responses: "How did the neighbours behave towards you when [client] was sick with AIDS"? (n = 31).

\begin{tabular}{cc}
\hline Response & $\begin{array}{c}\text { Percentage } \\
\text { giving response }\end{array}$ \\
\hline $\begin{array}{c}\text { The neighbours treated us well OR the } \\
\text { neighbours did not change their behaviour } \\
\text { when the client was sick with AIDS } \\
\text { Client's AIDS sickness was not known to the } \\
\text { neighbours }\end{array}$ & $39 \%$ \\
$\begin{array}{c}\text { The neighbours treated us badly when [client] } \\
\text { was sick with AIDS. }\end{array}$ & $28 \%$ \\
Don't remember & $3 \%$ \\
\hline
\end{tabular}

family), friends and neighbours were generally regarded positively, as they assisted with money, with in-kind livelihood support, and with emotional support. One woman expressed gratitude for the material and emotional help she had received:

$\mathrm{R}$ : People helped us who were concerned, they helped us very much.

I: How did they help you?

R: Money, some helped us with money, and others helped us in thoughts (emotionally). There is somebody who can help you in thoughts and this can be better than money. [That person] can advise you and encourage you, when your heart is about to go somewhere else, because of their encouragement and advice you come back to normal and settle to cope in the new state of life; telling you you can do like this, like this (TP 91).

Indeed, neighbours and friends were often represented as being very involved in the management of the illness, offering commentary and often conflicting suggestions as to what the respondents should do, to the point of intrusiveness.

Many women, especially those who had married into their husbands' community, said that neighbours were the ones who first alerted them to the likelihood that their husband's illness was AIDS, because they knew the husband's personal history better than newly arrived wives.

I: When they saw him get so sick, did they start to gossip or say things?

R: Eeh, they had things they could say.

I: Okay, how were they taking you and what were they saying?

R: They would talk and say ahh, she [respondent] did not know his first wife got sick a long time ago, now he has killed her [i.e. the respondent will die of AIDS like the first wife]. ... even people continued talking that she [the first wife] used to move with such and such a man and his wife died of the disease. ... That is when I got annoyed and forced him to go to [the health centre] for the blood test (TP 91).

Wives were advised variously to stay with their husbands; to leave them; to take them to the hospital, or to look out for their own health. These were complex decisions with far-reaching consequences. For instance, going to the hospital offered the possibility of relief, but doing so would eat up precious resources and the relief might only be temporary. Seeking out alternate healing strategies, such as faith healing, was also a gamble. Leaving a sick husband and returning to the natal home could mean foregoing any future claims of support on that husband or his family, as well as violating moral precepts which proscribed abandoning the helpless. Staying with the husband, however, not only meant ex-

\footnotetext{
${ }^{6}$ Thanks to Peter Rwakilembe for this clarification.
} 
posure to infection if the couple were still sexually active, but could also make for an awkward situation if the husband died under the wife's care, in that the wife could be blamed by her in-laws for not providi ${ }^{7}$.

However, neighbours' involvement was not always welcome. Several women spoke of pressure to take sick husbands to the hospital, even when the wife herself did not wish to do so.

Some [neighbours] thought that he was just sick of the usual fever but of course others know he had this disease. Some came to us telling us that "you people-they were counting us as sick people [i.e. both the husband and the wife were presumed to be sick, even though only the husband showed signs of AIDS] — what are you waiting for? Go to the hospital. Do you want to be bedridden? Go". They continued to talk to me like that. Recently he was having fever, much fever actually, [and] people kept asking me to tell him to go to the hospital. That sickness, has he forgotten his first wife who died [of AIDS]? Why cannot he go to the hospital? Then me, I would tell them now if I have told him to go to the hospital and he refuses, should I force him? That is what I tell them (TP 60).

\section{Keeping Household Aids Private}

Despite the low reports of stigma in the survey, interview respondents unequivocally preferred to keep their client's illness a secret, rather than disclose it. One woman described this preference forcefully:

R: They [neighbours] don't know that she was ever sick, and they cannot think of it.

I: And now do they know?

R: How will they know about it? You, do you see that anyone can recognize her [that she has AIDS]? Can you tell she is sick of this disease?

I: No. ... [but] suppose they ask you that they have heard that your daughter is sick.

R: That she is sick? Me, I tell them I do not know. I ask them if I am a doctor [who could diagnose AIDS]. ...

I: But if it happens and someone asks you?

R: Now asking me, how can they even start asking me? I tell you they cannot ask me at all (TP 79).

Some respondents said their client's sickness had not yet manifested itself visibly by the time the client started on treatment and began to regain health. For instance, one man said he was glad that his sister's fits of coughing were limited to nighttime, so that no one outside their homestead would hear it and start to speculate. Once the sickness did become observable, in the form of coughing, persistent weight loss, or fever, people might begin to talk.

Privacy was also hard to maintain when AIDS struck over and over again in the same family. One elderly man, who had lost members of three generations of his family to AIDS, said that he saw no point in even trying to con- ceal his grandson's sickness any more.

I: Was the relationship with others in your community not spoilt because your grandson had AIDS? Would you talk to people freely if they asked you what your grandson was sick of?

R: Now, this disease had killed his father and his mother, it had also killed his wife and his child. What would I hide from people now? That is obvious-they saw how the father and the mother died, and his wife....

I: Suppose people asked you what your client was suffering from, can you tell them the truth that your son and daughter-on-law died from AIDS?

R: Eeh, I can tell them-what can I hide? People know how his father died, it is the same way his mother died, and that is how he will die.

I: Do they ask you questions, what your client is suffering from?

R: They cannot ask me questions, when they know he is sick of the same disease. (HAART 25)

One woman explained that she was not hesitant to talk about AIDS in general, but would not acknowledge that her own daughter was sick. She was clearly ambivalent about stigma - she would talk about the disease in the abstract, but not admit a personal connection.

If you ask me about the general HIV/AIDS I can tell you or explain to you what I know, but I cannot tell you that my daughter has the disease. I can help you and tell you to go for testing but I will not tell that I have someone in my home with it. I can tell you to go to the hospital if you are sick and even tell you that those who are going to the hospital, I see them getting better. That is how I can help you. But I cannot tell you that my daughter has the disease too (HAART 74).

Many respondents kept their fears and concerns about their patient's deteriorating health to themselves, rather than let these become general knowledge.

I: As a wife whenever you got such worries did you tell anyone or you kept everything to yourself?

$\mathrm{R}$ : I kept everything to myself as people also have their problems and worries, why then should I make them carry my burden? I didn't tell any person.

I: Why?

R: Though you tell [some] people, others will start laughing behind your back. You know people in the village... So that was why I kept my secrets to myself-got worried alone and became happy alone. (HAART 49)

The desire for secrecy extended even to the patient him or herself. TPs said they did not want their patient to know what a burden s/he was on the family, and did not want to share new of the growing family troubles. One young woman who took care of her aunt when she was sick said that no one, not even the patient, knew of her increasing difficulties coping. If her aunt knew how difficult things were, "she would feel bad and hate herself. I 
could not do that to her” (TP 86).

\section{Rejection and Gossip}

Although stigma does not appear to be intense, over a quarter of respondents said they had experienced it. Some of these incidents took place in the context of ongoing bad blood between families, such that AIDS became yet another item in a longstanding quarrel. For instance, one boy reported that his neighbor would not let him or his brother come and play with her own children because the boy's mother had AIDS. Now that the mother is improving on drugs, the boy said, the hostile neighbour switched her criticism of the boy's mother to denigration of the mother's housekeeping and childraising skills. Similarly, another woman reported that that her own experiences with rejection and stigma were conditioned by ongoing disputes about land between her household and a neighbouring one: the neighbours spread the word that everyone in the household was going to die, and that the neighbours would thereby get their hands on the household's farmland.

When respondents did mention negativity generated by AIDS itself, the element of ADIS which figured most strongly was its perceived lethality, rather than its modes of sexual transmission. While individuals might suspect their spouses of sleeping around, the idea that a person with AIDS was a "walking corpse" appeared to be a more perful engine of ostracism than the sexual behaviour implied by AIDS infection. One man, for instance, said that his mother kept her HIV status hidden from all those except others whom she knew to be HIV positive, because she did not want other to "backbite her, like that one is a moving corpse” (TP 86). When asked to describe the negative attention they had received from friends and neighbours, respondents predominantly gave examples in which expected mortality from AIDS was the source of mockery, avoidance or gossip.

I: Now let's say, friends and neighbours, how would they behave towards you when your husband was sick?

$\mathrm{R}$ : The neighbours, for them they would come to see with their own eyes that we were sick with silimu. (Laughs)

I: They would laugh at you?

$\mathrm{R}$ : Yes, that [because] is it going to kill us. (HAART 82)

I: Okay, the neighbours and the relatives, when they realized that [her husband] is getting so sick, how did they behave towards you?

$\mathrm{R}$ : They were laughing at us, sort of, that the disease is going to finish [us]. [We] will all die and go away. (TP 51)

\section{Avoiding Requests for Help}

Some of this reaction to the lethality of AIDS may have been practical self-protection. AIDS is an expensive illness, which drained families' resources and forced them to seek help from others. One man described at length how his grandson's illness strained the resources of his entire network:

I: Okay, all those that helped you, like your daughter, did they find any problems in helping your grandchild?

$\mathrm{R}$ : Of course in helping him they found difficulties. They had to help him, if they didn't help he would have died. They went to the hospital, ... they had to buy food while at the hospital. And you know the client can have appetite for different foods and lose appetite for all of them the moment he starts eating or before he starts eating, some [relatives] could buy every food he wanted, and you can't count all the money spent on that. All you can think of is to keep him alive, even if I sell all the land we have.

I: ... Those who were helping you care for him, didn't they find it a problem to be with him in the hospital, to [care for] him, didn't they find any difficulties?

R: They were seeing problems, but they realized that this person could die. Had we pulled out and gotten tired [of providing assistance], he would not be living.

I: ... So you could not just leave him to die?

R: Now you have understood it. (TP 25)

Respondents described extended periods of time, years in some cases, of seeking help for the sick person, paying for transportation and treatment of opportunistic infections, and losing whatever resources the sick person might have contributed to the household. As time passed and the patient's condition continued to deteriorate, expenditure on the patient seemed increasingly futile ${ }^{8}$.

By keeping their distance, other families could protect themselves against appeals for handouts and other assistance. One woman said that she stopped her husband from telling neighbours about his sickness because she feared that he would drive people away with what might be interpreted as requests for assistance:

He tried telling people that he wanted to go to the hospital, but he had no money; but whenever people went away [were not present], I stopped him from telling people such things as people also have their own problems. It is shaming. I told him not to do it again. (HAART ID

${ }^{7}$ This fear of blame was not just the province of wives, but of all spouses who were living as "outsiders" in their husband or wife's natal community. Below, an excerpt from a man who lived with his wife's family:

I: Before [his wife] started on drugs, were you worried about anything? R: You know, sometimes, but not always, I used to worry [about what would happen] if she died in my hands when I don't [belong to] their home. I would get worried especially being an outsider.

I: Did you share your worries with anyone?

R: I am an old person and on top of that an outsider, so I kept my secrets between me and my God because I have no one else to tell. (TP 50)

${ }^{8}$ See [29] for the gradual withdrawal of support for people with ongoing illnesses suspected to be AIDS in Namibia. 
93)

A teenage boy found that the bonds of reciprocity between his household and their neighbours broke down once his mother was no longer able to participate in the lending and borrowing of goods:

I: What was your relationship with your friends and neighbours like when your mother became sick?

R: People treated us badly. ... Whenever we borrowed certain things, people claimed we were inconsiderate, but when she got better she tried and availed everything [i.e. returned everything which had been borrowed].

I: What did you borrow that made people complain?

R: Hoes, pangas.

I: How was the relationship like before mother became sick?

$\mathrm{R}$ : It was very good. We had a lot of property-a lot of things, and I think the neighbours preferred the things to the owners. I think they pretended to be our friends but I discovered they were not when our parents got sick and Daddy died (TP 24)

AIDS in the household also slashed families' abilities to fulfill their obligations and responsibilities within reciprocal social networks. One woman described how her husband's sickness made friends and neighbours doubt whether the household would be able to engage in mutually supportive activities, and began dropping the afflicted household from gatherings and group events:

Before he got sick, the relationship between friends and neighbours was good as we fulfilled all our plans, but after we became sick, people started to say that we are sick, why then should be invited or called upon for any gathering? They started despising us, saying [even if] they called me or invited me, I had no one to leave at home to attend to the sick man. (HAART 49)

Other respondents spoke of having to give up going to gatherings where social capital is generated and distributed, such as church services or meetings, when their patient was too sick to be left alone.

People with HIV were perceived as unwilling to work hard and invest in the future, attributes which may have made them less desirable as participants in relationships based on reciprocity. One woman described her husband selling off everything they had accumulated:

We had so many assets and he sold them, he sold the land, saying "ah, since I am about to die [I don't need these things]" ... He still has debts, he has not been the same since he got to know he has the HIV virus. (HAART 91)

One man, in interviews conducted in 2007 for an earlier iteration of this project, referred to the tendency of people with AIDS to "eat everything" [i.e. consume all available resources] rather than "working hard to develop", because the person with AIDS did not anticipate living to see the benefits of developing his or her re- sources (Interview 1). This perceived orientation towards consumption rather than investment may also contribute to neighbours' unwillingness to involve households with AIDS in projects.

\section{9. “Moving Corpses": Between Life and Death}

In addition to the practicality of not investing time and effort in households which might not return it, there may also have been a deeper, more visceral reaction against the idea of a "moving corpse" - of death in life-behind aversion to people with AIDS. Accounts of negative gossip from interviewees focused on the fact of mortality from AIDS, the inevitability of death, and the juxtaposetion of impending death and the afflicted person ${ }^{9}$. Symptoms like persistent diarrhea, fevers, weakness and excessive coughing were all mentioned by TPs as manifesttations of AIDS, and often as diagnostic of the disease. Yet these unpleasant and often repulsive conditions were absent from TPs' accounts of others' reactions. Instead, the inevitability of death, corporealized by the person suffering from AIDS, was the dominant motif ${ }^{10}$.

These reactions call to mind the work of Victor Turner on liminality, life and death [39]. Turner defined liminality as the condition of being between two statuses, neither wholly one thing nor wholly another: in the case of AIDS, between being alive and being dead. In Turner's formulation, liminality is part of the process of ritual transformation, bracketed by separation from one's former status and by reintegration into the community in a different form-as a full adult, in the case of initiation rites, or as an ancestral spirit, in the case of funeral rites. For the "walking corpses" in Kabarole, the liminality extended from the time that they were identified as having HIV, with its connotations of death, to the actual death of the body.

Now that treatment has become available, re-integration into society may be an option for those who were regarded as dead people awaiting their final exit. As patients recovered, respondents stressed the amazement (often with religious overtones) among friends and neighbours that the client had somehow cheated death. The apparent repeal of the AIDS death sentence received more attention than any of the more visible manifestations of treatment, such as physical transformation.

\footnotetext{
${ }^{9}$ See also [24] (16) for more examples of the conflation of AIDS and death.

${ }^{10}$ In a journalistic piece on euphemisms for AIDS [38], slang terms which referenced the proximity of death out numbered the terms which actually described the disease (such as "skinny enough to stand on a nail”). Euphemisms for AIDS from Africa included "excuse me, grave"; "sickness that ends in death"; "God is tracking you [i.e. to bring you to Him]"; "red card [i.e. you are being sent out of the game]" departure lounge [i.e. awaiting a trip to the grave]" or "go slow [slow progress towards death]".
} 
When she gained her health back and stood on her feet, they said... "The person you thought was going to die today or tomorrow, hasn't she been risen and walking!” (TP 27).

I: Now when he [husband] got well and strong, what did they start to say?

$\mathrm{R}$ : If they see him now ... [silence]

I: Did they continue to gossip about you?

R: Ah no, they cannot gossip. ... They say "We were prepared to eat the goat, but now it seems difficult" [i.e. the neighbours were preparing for a funeral meal, but now that prospect is unlikely]" (HAART 82).

\section{Moral Stigma and AIDS}

In these accounts, what is not mentioned is as a significant as what is. While everyone was certainly aware that HIV is sexually transmitted, and while everyone could produce elaborate accounts of sexual networking to explain the provenance of a particular infection, respondents did not report being shamed or disdained because the sick person in their house had engaged in improper sex. AIDS was not described as a moral issue, or retribution for those who violated social norms.

This lack of moralizing may reflect the generalized nature of the epidemic in Kabarole. The idea that "anyone can get AIDS" is prevalent in local talk about the disease, and while this idea is a staple of standard HIV prevention rhetoric, it is also close to the truth in this particular community.

\section{Conclusions}

From this paper, we draw three conclusions; one empirical, one theoretical and one programmatic. On an empirical level, we find that AIDS stigma does not appear to be very intense in this high-prevalence setting. TPs attribute this to the acceptance of AIDS as part of life which has developed over the last three decades. Where stigma does exist, it takes the form of isolation and gossip, and appears to be connected more to the perceived lethality of AIDS than to sexual mores or moral judgments.

On a more theoretical level, the most prominent theme in reported stigma is juxtaposition of life and death-a person with AIDS is a liminal entity, no longer really among the living, but not quite yet dead. This liminality produces psychological discomfort among others, as well as the more practical response of not investing too much effort in those who cannot reciprocate. Thus, liminality thus weakens the channels of social networks through which help might otherwise flow, and disrupts patterns of reciprocity and mutual support.

What does this mean for programming? The most hopeful speculation arising from this study is that treat- ment may decrease stigma. If stigma is driven by the presumption of inevitable death, treatment which takes away that inevitability may undermine the basis of stigma. Longitudinal research which follows the social and psychological trajectory of clients and their families might explore the possibility that treatment initiates a return to full membership in the community of the living. While treatment cannot cure AIDS, it can remove the taint of mortality.

\section{REFERENCES}

[1] A. Castro and P. Farmer, "Understanding and Addressing AIDS-Related Stigma: From Anthropological Theory to Clinical Practice in Haiti," American Journal of Public Health, Vol. 95, No. 1, 2005, pp. 53-59.

doi:10.2105/AJPH.2003.028563

[2] T. Rosenberg, "When a Pill Is Not Enough," New York Times, 6 August 2006.

[3] E. G. Benotsch, D. W. Seal, L. Y. Stevenson, C. A. Sitzler, J. A. Kelly, L. M. Bogart and C. Gore-Felton. "Stigma, AIDS and HIV Prevention in Africa: Reports from Community Organizations Providing Prevention Services," Journal of Human Behavior in the Social Environment, Vol. 18, No. 3, 2008, pp. 329-349. doi:10.1080/10911350802427571

[4] P. Piot, “Stigma Major Barrier to Fighting AIDS,” 2002. http://www.aegis.org/DisplayContent/DisplayContent.asp $\mathrm{x}$ ?SectionID=128868

[5] B. Ki-Moon, “The Stigma Factor,” 2008. http://www.unaids.org.cn/uploadfiles/20080902175623.doc

[6] E. Goffman, "Stigma: Notes on the Management of Spoiled Identity,” Simon \& Schuster, New York, 1963.

[7] S. Sontag, "Illness as Metaphor and AIDS and Its Metaphors,” Picador, New York, 2001.

[8] T. de Bruyn, "HIV-Related Stigma and DiscriminationThe Epidemic Continues," Canadian HIVIAIDS Policy \& Law Review, Vol. 1, No. 1, 2002, pp. 8-14.

[9] P. S. Dhlamini, D. Wantland, L. N. Makoae, M. Chirwa, T. W. Kohi, M. Greeff, J. Naidoo, J. Mullan, L. R. Uys and W. L. Holzemer, "HIV Stigma and Missed Medications in HIV-Positive People in Five African Countries," AIDS Patient Care \& STDs, Vol. 23, No. 5, 2009, pp. 377-387. doi:10.1089/apc.2008.0164

[10] C. E. Abadia-Barrero and A. Castro, "Experiences of Stigma and Access to HAART in Children and Adolescents Living With HIV/AIDS in Brazil," Social Science \& Medicine, Vol. 62, No. 5, 2006, pp. 1219-1228. doi:10.1016/j.socscimed.2005.07.006

[11] A. Castro and P. Farmer, "Understanding and Addressing AIDS-Related Stigma: From Anthropological Theory to Clinical Practice in Haiti," American Journal of Public Health, Vol. 95, No. 1, 2005, pp. 53-59. doi:10.2105/AJPH.2003.028563

[12] R. Parker and P. Aggleton, "HIV and AIDS-Related Stigma and Discrimination: A Conceptual Framework and Implications for Action," Social Science \& Medicine, 
Vol. 57, No. 1, 2002, pp. 13-24. doi:10.1016/S0277-9536(02)00304-0

[13] S. Babalola, A. Fatusi and J. Anyanti, "Media Saturation, Communication Exposure and HIV Stigma in Nigeria," Social Science \& Medicine, Vol. 68, No. 8, 2009, pp. 1513-1520. doi:10.1016/j.socscimed.2009.01.026

[14] R. Stephenson, "Community Factors Shaping HIV-Related Stigma among Young People in Three African Countries,” AIDS Care, Vol. 21, No. 4, 2009, pp. 403410. doi:10.1080/09540120802290365

[15] M. J. Visser, J. D. Makin, A. Vandormael, K. J. Sikkema and B. W. C. Forsyth, "HIV/AIDS Stigma in a South African Community,” AIDS Care, Vol. 21, No. 2, 2009, pp. 197-206. doi:10.1080/09540120801932157

[16] M. Boulay, L. Tweedie and E. Fiagbe, "The Effectiveness of a National Communication Campaign Using Religious Leaders to Reduce HIV-Related Stigma in Ghana," African Journal of AIDS Research (AJAR), Vol. 7, No. 1, 2008, pp. 133-141. doi:10.2989/AJAR.2008.7.1.13.441

[17] J. Chiu, J Grobelaar, K. Sikkema, A. Vandermoel, N. Bomela and T. Kershaw, "HIV-Related Stigma and Social Capital in South Africa,” AIDS Education and Prevention, Vol. 20, No. 6, 2008, pp. 519-530. doi:10.1521/aeap.2008.20.6.519

[18] H. Muyinda, J. Seeley, H. Pickering and T. Barton, "Social Aspects of AIDS-Related Stigma in Rural Uganda," Health \& Place, Vol. 3, No. 3, 1997, pp. 143-147. doi:10.1016/S1353-8292(97)00010-5

[19] S. Kalichman and L. Simbayi, "HIV Testing Attitudes, AIDS Stigma, and Voluntary HIV Counselling and Testing in a Black Township in Cape Town, South Africa," Sexually Transmitted Infections, Vol. 79, 2003, pp. 442447. doi:10.1136/sti.79.6.442

[20] C. Campbell, Y. Nair, S. Maimane and J. Nicholson, "'Dying Twice: A Multi-Level Model of the Roots of AIDS Stigma in Two South African Communities," Journal of Health Psychology, Vol. 12, No. 3, 2007, pp. 403-416. doi:10.1177/1359105307076229

[21] M. J. Visser, T. Kershaw, J. D. Makin and B. W. Forsyth, "Development of Parallel Scales to Measure HIV-Related Stigma," AIDS \& Behavior, Vol. 12, No. 5, 2008, pp. 759-771. doi:10.1007/s10461-008-9363-7

[22] G. Letamo, "Prevalence of, and Factors Associated with, HIV/AIDS-Related Stigma and Discriminatory Attitudes in Botswana,” Journal of Health, Population \& Nutrition, Vol. 21, No. 4, 2003, pp. 347-357.

[23] L. Nyblade, R. Pande, S. Mathur, K. MacQuarrie, R. Kidd, H. Banteyerga, A. Kidanu, G. Kilonzo, J. Mbwambo and V. Bond, "Disentangling HIV and AIDS Stigma in Ethiopia, Tanzania and Zambia,” International Centre for Research on Women, Washington, 2003.

[24] J. Ogden and L. Nyblade, "Common at Its Core: HIVRelated Stigma Across Contexts,” International Centre for Research on Women, Washington, 2006.

[25] C. I. Ulasi, P. O. Preko, J. A. Baidoo, B. Bayard, J. E. Ehiri, C. M. Jolly and P. E. Jolly, "HIV/AIDS-Related Stigma in Kumasi, Ghana,” Health \& Place, Vol. 15, No. 1, 2009, pp. 255-262. doi:10.1016/j.healthplace.2008.05.006

[26] L. Nyblade, K. MacQuarrie, G. Kwesigabo, A. Jain, L. Kajula, F. Philip, W. Tibesigwa and J. Mbwambo, "Moving forward: Tackling Stigma in a Tanzanian Community,” Population Council, Washington, 2008.

[27] M. Boulay, L. Tweedie and E. Fiagbe, "The Effectiveness of a National Communication Campaign Using Religious Leaders to Reduce HIV-Related Stigma in Ghana,” African Journal of AIDS Research, Vol. 7, No. 1, 2008, pp. 133-141. doi:10.2989/AJAR.2008.7.1.13.441

[28] A. Chimwaza and S. Watkins, "Giving Care to People with Symptoms of AIDS in Rural Sub-Saharan Africa," AIDS Care, Vol. 16, No. 7, 2004, pp. 795-807. doi:10.1080/09540120412331290211

[29] F. Thomas, "Stigma, Fatigue and Social Breakdown: Exploring the Impacts of HIV/AIDS on Patient and Carer Well-Being in the Caprivi Region, Namibia," Social Science \& Medicine, Vol. 63, No. 12, 2006, pp. 3174-3187. doi:10.1016/j.socscimed.2006.08.016

[30] V. Hosegood, E. Preston-Whyte, J. Busza, S. Moitse and I. M. Timaeus, "Revealing the Full Extent of Households' Experiences of HIV and AIDS in Rural South Africa," Social Science \& Medicine, Vol. 65, No. 6, 2007, pp. 1249-1259. doi:10.1016/j.socscimed.2007.05.002

[31] W. Kipp, D. Tindyebwa, T. Rubaale, E. Karamagi and E. Bajenja, "Familt Caregivers in Rural Uganda: The Hidden Reality," Health Care for Women International, Vol. 28, No. 10, 2007, pp. 856-871. doi:10.1080/07399330701615275

[32] B. Ndyanabangi, W. Kipp and H. J. Diesfeld, "Reproductive Health Behaviour among In-School and Out-ofSchool Youth in Kabarole District, Uganda," African Journal of Reproductive Health, Vol. 8, 2004, pp. 55-67. doi:10.2307/3583393

[33] W. Kipp, C. Masheisha, F. von Sonnenburg and P. Weiss, "Influence of Personal Experience of Dying AIDS Patients on Attitude and Sexual Behaviour in Kabarole District, Uganda,” AIDS, Vol. 8, No. 3, 1994, pp. 392-398.

[34] L. Adeokun, "Household Functioning and AIDS," Vol. 8, Quantitative Data: Combined 3-District Report (Masaka, Kabarole, Rukungiri), Institute of Statistics and Applied Economics, Makerere University, Kampala, 1996.

[35] A. Kaler, "Gender-as-Knowledge and AIDS in Africa: Shifting Concepts, Malawian Stories, Historical Contexts and a Cautionary Tale," Infectious Diseases and the Social Sciences Workshop, Cornell University, Ithaca, 2007.

[36] N. Bedingfield, “The Psychosocial Impact of Highly Active Antiretroviral Therapy on Patients and Caregivers in Western Uganda: A Qualitative Study,” Thesis for Master of Public Health, University of Alberta, Edmonton, 2008.

[37] R. Jewkes, "Beyond Stigma: Social Responses to HIV in South Africa,” The Lancet, Vol. 368, 2006, pp. 430-431. doi:10.1016/S0140-6736(06)69130-7

[38] IRIN PLUS News, 2009. http://www.plusnews.org/Report/78809/AFRICA-Mind-y our-language-a-short-guide-to-HIV-AIDS-slang

[39] V. Turner, "The Forest of Symbols: Aspects of Ndembu Ritual,” Cornell University Press, Ithaca, 1967. 